\title{
DELIBERACIÓN EN BIODERECHO
}

Dora Nevares-Muñiz ${ }^{1}$

\section{RESUMEN}

Este ensayo expone la relación entre la bioética y el derecho, en ánimo de elaborar una modelo de deliberación adjudicativa para atender asuntos relacionados con los avances de la ciencia y biotecnología para los cuales no hay legislación positiva o precedente judicial. En la primera parte se explican los términos bioética, bioderecho, biojurídica, y la relación entre ética, moral y derecho. Le siguen consideraciones teóricas sobre la deliberación bioética y la adjudicación en derecho. La última parte expone el modelo propuesto para adjudicación de asuntos en bioderecho.

\section{PALABRAS CLAVES}

Bioética. Bioderecho. Biojurídica. Modelos en Bioderecho. Ética. Moral. Derecho. Dignidad.

\section{ABSTRACT}

This essay describes the relationship between bioethics and law in view of preparing an adjudicative and deliberative model to settle matters arising in connection with advances in science and biotechnology but which are not yet regulated under positive law or for which there is no binding precedent. The first section explains the terms bioethics, biolaw, and biolegal and the relationship between ethics, moral, and law. The next section discusses theoretical considerations about bioethics deliberation and legal adjudication. The final section describes a proposed model for adjudication in biolaw.

\section{KEY WORDS}

Bioethics. Biolaw. Biolegal. Biolaw. Ethics. Moral Models. Law. Dignity.

INTRODUCCIÓN Y CONSIDERACIONES TEÓRICAS

\section{Alcance y justificación}

Ante las nuevas realidades creadas por los avances científicos en la biología con respecto al inicio, transcurso y fin de la vida, tanto de los seres humanos como de los demás seres vivos y del planeta, el Derecho debe tomar posiciones. Legislar no es tarea fácil; tampoco resolver las controversias por la vía adjudicativa si se trata de atender asuntos complejos en proceso de innovación científica y en plena expansión. Entre otros, asuntos sensibles que afectan los intereses de grupos con pluralidad de códigos morales tales como: la determinación del momento en que ocurre la muerte o del inicio de la vida, aborto, eutanasia, suicidio asistido, transexualidad, clonación, reproducción asistida, ingeniería genética, alimentos transgénicos, biote- rrorismo, trasplantes de órganos, el proyecto genoma humano y uso de sujetos humanos en la investigación. Además, han surgido otros asuntos inexistentes en décadas anteriores como la determinación de la propiedad de datos genéticos, transformaciones en la prestación de los servicios de salud como resultado de los avances en la medicina, y la necesidad de la preservación de la biodiversidad ante la finitud de los recursos planetarios.

1 J.D., Universidad de Puerto Rico; M.A.; Ph.D., University of Pennsylvania; Catedrática, Facultad de Derecho, Universidad Interamericana de Puerto Rico. Parte de la investigación fue realizada durante un visiting fellowship, en Oxford University, verano 2012. Esta ponencia fue presentada en el IX Congreso Latinoamericano y del Caribe de Bioética, celebrado en Guanajuato, México, 17-20 abril 2013. 
Se recurre al derecho para determinar lo que es tolerable desde la legalidad ante las distintas formas de intervenir con el fenómeno de la vida como resultado de los avances científicos; para que reglamente y provea sanciones a prácticas potencialmente lesivas para el ser humano y su entorno; para proteger derechos de las personas, evitar daños personales y al ambiente, y como mecanismo para resolver conflictos específicos relacionados con el impacto de los desarrollos científicos sobre la vida humana.

\section{Definiciones: bioética, biode- recho, biojurídica}

La bioética es el "estudio sistemático de la dimensión moral de las ciencias de la vida y de la salud, utilizando diversas metodologías éticas en un marco interdisciplinario."2 Para Santos Vargas, la "bioética es la disciplina que se ocupa del estudio y la reflexión en torno a la dimensión e implicaciones humanísticas y éticas de los avances de las ciencias, las profesiones de la salud y de la ecología. Es además, una metodología de solución racional de los problemas que surgen de las acciones y de la toma de decisiones que comportan problemas y dilemas éticos en los escenarios científicos y clínicos, tanto a nivel personal como colectivo."
Se trata de una disciplina en construcción ante los avances de la tecnología, los problemas macro globales y la perplejidad que nos causan; para la toma de decisiones en contextos de incertidumbre, de cara al presente y a las futuras generaciones, y en solidaridad con el hábitat. ${ }^{4}$ Se plantea que la bioética no debe limitarse considerar sólo las situaciones emergentes surgidas como consecuencia de los avances científicos y tecnológicos en la vida humana y del planeta, sino que debe incluir también la consideración de situaciones persistentes en la sociedad, tales como la discriminación de la mujer, la exclusión social, el racismo, inequidad en la distribución y acceso a los servicios de salud, maltrato a los vulnerables, violencia, aborto, contracepción, eutanasia, contaminación ambiental, entre otras. ${ }^{5}$

El bioderecho es la respuesta del mundo del Derecho al surgimiento de la bioética. Es la rama del Derecho que tiene que ver con la aplicación de los avances científicos a los seres humanos. ${ }^{6}$ El derecho se presenta como un límite o sistema de gestión social ante el llamado "miedo bioético" ante los avances de la ciencia. ${ }^{7}$ Se recurre al Derecho para establecer los límites de riesgo permitido ante los asuntos que surgen en es- cenarios científicos y clínicos cuando se trata del fenómeno de la vida. El bioderecho atiende los asuntos bioéticos, o conflictos que surgen en el ámbito de las relaciones humanas como consecuencia de la incorporación de las nuevas tecnologías a las ciencias de la salud, al ambiente y a la ecología, desde la perspectiva del derecho.

En cambio, la biojurídica aborda el estudio de las cuestiones bioéticas desde la filosofía jurídica. Se interesa en justificar los principios jurídicos, en los que se apoyaría el bioderecho o la biolegislación. Está en manos de los filósofos del Derecho. Para Aparisi Millares, "a la biojurídica le corresponde -al igual que a la filosofía del derecho- reflexionar sobre las normas vigentes, a la luz del principio de la dignidad humana y de los derechos humanos. Otro reto de la biojurídica: incluir los derechos bioéticos en el contexto de los derechos humanos, garantizando al ser humano las condiciones para ejercer plenamente su identidad racional y la propia humanidad". ${ }^{8}$

En países de la tradición jurídica civilista se habla de bioderecho, biojurídica, biojurisprudencia y biolegislación. En los Estados Unidos se utiliza biolaw o bioethics law. Refi-

Encyclopedia of Bioethics, W.T.Reich, ed. New York, Simon \&Schuster, Macmillam, 1995, v.1, xxi.

Santos y Vargas, L., Bioética Crítica. San Juan, Instituto Hostosiano de Bioética, UPR, 2006: p.6.

Cely Galindo,G., Bioética Global. Madrid, Siglo del hombre, 2009.

Garrafa, V., "Epistemiología de la Bioética-enfoque latinoamericano.” Revista Brasileira de Bioética, 2007, vol. 3(núm. 3): pp.344-359.

Vila-Coro, M. Introducción a la Biojurídica. Madrid, Universidad Complutense, 1995.

D “Agostino, F., “Bioética y Derecho,” Acta Bioethica, año 8, núm. 2: pp.177-182.

8 Aparisi Millares,A. Bioética Bioderecho y Biojurídica, 2008. En http://www2.uah.es/filder/bioetica_bioderecho_ biojuridica.pdf (consultado 1/marzo/2013). 
riéndose a esa acepción general, un autor dice que biolaw es un neologismo que describe todas las ciencias del derecho relacionadas con las ciencias de la vida. ${ }^{9}$

El "puente" o la secante entre la bioética y el Derecho son los derechos humanos. La reflexión bioética aporta datos, reflexiones y metodologías útiles al bioderecho; mientras que, el derecho, el respaldo que implica la coacción legal. Según Diego Gracia “el bioderecho sin la bioética es ciego, y la bioética sin el derecho resulta vacía." 10

\section{Adjudicación de controver- sias en Derecho}

En los países de la tradición anglosajona en derecho se adjudican las controversias utilizando por lo general el modelo positivista. Aunque Puerto Rico es una jurisdicción mixta y el Art. 7 del Código Civil dispone para la aplicación de la equidad, ${ }^{11}$ el modelo positivista de adjudicación tiene gran arraigo. $\mathrm{El}$ mismo está basado en la norma escrita y el precedente judicial es el utilizado por excelencia en la adjudicación de controversias o casos jurídicos por los tribunales. Cuando sur- gen asuntos para los cuales no hay ley positiva, ni precedente, lo cual adquiere relevancia ante las controversias que se suscitan como resultado de los avances de la biotecnología, se hace necesario recurrir a un modelo de adjudicación basado en los principios, valores morales y los derechos humanos. A continuación se presentan varios modelos de adjudicación jurídica y de deliberación bioética, en ánimo de sugerir un modelo integrado para la deliberación adjudicativa de controversias en bioderecho.

\section{Modelos de DELIBERACIÓN PARA LA ADJUDICACIÓN JURÍDICA}

Etica, moral, derecho y adjudicación

La precisión de los términos ética, moral y su relación con el derecho, para fines de este escrito es pertinente. Ferrer define el término ética como "la disciplina que estudia la conducta humana desde el punto de vista de los valores y principios morales." 12 Mientras que, la moral se refiere a "los códigos normativos-conjunto de principios y normas-que prescriben las conductas apropiadas en una cultura, pueblo, tradición reli- giosa o grupo profesional."13 En cambio, el derecho se ocupa de las conductas externas y alterativas que ponen al sujeto en relación con el otro, en el contexto del comportamiento de las personas en sociedad y como parte de un cuerpo político. El Derecho requiere de un Estado y de personas sujetos de derechos y deberes, y su fin último es la justicia.

El ordenamiento jurídico está al menos en parte, al servicio del orden moral en cuanto codifica y protege los mínimos morales esenciales para la convivencia social, sin que ello signifique que el derecho quede reducido a dichos mínimos. Tampoco lo moral queda reducido a dichos mínimos. ${ }^{14}$ Esos valores mínimos son: dignidad, autonomía, respeto a la voluntad de conciencia, respeto a la igualdad fundamental de todos ante la ley. Las leyes positivas no deben transgredir las exigencias fundamentales de la moralidad. ${ }^{15}$ José Trías Monge explica que: "la moralidad es parte inextricable del derecho. Los juicios jurídicos entrañan necesariamente juicios éticos. Toda sentencia se basa en juicios valorativos. La contención de que el derecho se compone estrictamente de

9 Chen, j., "Biolaw: Cracking the Code", Kansas Law Review. 2008, vol. 56: p.1029.

10 Gracia, D., Fundamentos de la Bioética. Madrid, Triacastela, 2007: p. 576. Se refiere ese autor a que la bioética sin el concurso del derecho podría desarrollarse como una moral de máximos que pretenda imponer la moral personal a los demás. En cambio, el derecho sin el concurso de la bioética podría aceptar como legal conductas que atentan contra los principios fundamentales de cada sociedad.

11 "Cuando no haya ley aplicable al caso, el tribunal resolverá conforme a equidad, que quiere decir que se tendrá en cuenta la razón natural de acuerdo con los principios generales del derecho, y los usos y costumbres aceptados y establecidos." 31 L.P.R.A. § 7.

12 Ferrer, J.J., Deber y Deliberación. Mayaguez, UPR, CEPA, 2007: p.14.

13 id.

14 Véase, Ferrer, J.J, Deber y Deliberación, 2007: pp.27-28; Gracia, D., Fundamentos de Bioética, 2007: pp. 75-582.

15 Distíngase que la moralidad es universal en la especie humana. Así, una ley inmoral será aquella que atente contra los derechos fundamentales de las personas: dignidad, libertad, igualdad, justicia. Lo que son plurales son los códigos morales de las personas. 
reglas y principios es insostenible. La construcción de una teoría pura del derecho en esta sociedad no parece prudente. Aun los nuevos positivistas analíticos como Hart reconocen el papel de los valores en la estructuración de las reglas y la formulación del derecho." 16

Asímismo, Ronald Dworkin, postula que los derechos morales y naturales son previos al Estado. Los derechos humanos básicos no dependen de la cultura, sino que son verdades objetivas que emanan de la humanidad de cada ser humano. Por eso son consustanciales a la dignidad humana. ${ }^{17}$ Las constituciones nacionales justifican políticamente los derechos morales o humanos.

Dworkin rechaza la teoría positivista pura de interpretación jurídica, que establece una distinción rígida entre derecho y moral. ${ }^{18}$ Para los positivistas, entre ellos H.L. Hart ${ }^{19}$, la norma se aplica o no se aplica a la situación de hechos. El resultado cuando no aplica la norma, es recurrir a aplicar la discreción judicial. El modelo positivista utiliza la discreción judicial, para elegir entre diferentes cursos de acciones válidas cuando no exista respuesta jurídica precisa o donde existe más de una interpretación razonable. El juez en el modelo positivista no tiene otra salida que escoger prudentemente la opción que estime adecuada, entonces, en opinión de Dworkin, el juez crea una norma para el caso en concreto.

Dworkin habla de un principio adjudicativo de integridad para la consideración de controversias jurídicas. Instruye a los jueces a que identifiquen derechos y deberes legales, hasta donde sea posible, sobre la suposición de que todos fueron creados por un mismo autor que expresa una correcta concepción de justicia y equidad. La integridad requiere que se interprete el orden jurídico vigente como expresión de un esquema coherente de principios de justicia, equidad y debido proceso en la relación adecuada. Los casos difíciles tienen una respuesta correcta. Que no haya normas específicas, no significa que no sean aplicables los principios de justicia y equidad ${ }^{20}$. El juez debe acoger la teoría que mejor justifique y explique el derecho histórico y el derecho vigente; aun en caso en que esté ausente la norma positiva.

Como para Dworkin es imposible separar el razonamiento jurídico de la moral, propone una teoría de adjudicación que da prioridad a los principios y directrices; mientras que la norma ocupa un lugar secundario. Las directrices (policies) se refieren a objetivos sociales a alcanzar y que se consideran beneficiosos socialmente. Los principios se refieren a la justi- cia como equidad. ${ }^{21}$ Estos permiten al juez dar razones para decidir en un sentido determinado, e informan o sustentan las normas jurídicas, de manera que el juez puede desatender la literalidad de la norma cuando viola un principio específico que considera más importante. La relevancia de un principio sobre otro se establece en relación a la controversia o caso concreto objeto de la adjudicación. La teoría de adjudicación es la disciplina en que se observa más de cerca y en situaciones más concretas el choque entre los valores de distinto orden y se intenta su armonización. ${ }^{22}$

En bioderecho, es preciso adjudicar asuntos en que está en controversia el final o el inicio de la vida, o hasta donde se puede manipular la misma, lo que presenta dilemas morales en ocasiones insalvables. Ante la imposibilidad de encontrar consensos es preferible la vía judicial que la legislativa. Se trata de encontrar el curso legal y moralmente óptimo para resolver la controversia. Como dice Trías Monge, "no hay fórmulas simples y salvadoras, varitas mágicas para desvanecer o descifrar misterios y ofrecernos pródigamente en todo caso el significado de la ley." ${ }^{23}$

\section{La aportación del modelo de ética médica}

En la ética médica se ha desarrollado un paradigma, basado

6 Trías Monge, J. Teoría de la Adjudicación, San Juan, Editorial UPR, 2000: 395-396.

Dworkin, R., Justice for Hedgehogs, Harvard U Press, 2011.

Dworkin, R., Taking Rights Seriously. Harvard U. Press, 1978, 5ta ed. 1987.

Hart, H.L., The Concept of Law. Oxford U., 2nd ed, 1997.

Dworkin, Taking Rights Seriously, 1978, 5ta ed.1987.

21 Dworkin fue Influenciado por los principios de liberalismo (libertad e igualdad) y por John Rawls en cuanto a la concepción de la justicia como equidad. Véase, Rawls, J., A theory of Justice, Harvard U. Press, 1971, rev. ed. 1999.

22 Trías Monge, J. Teoría de la Adjudicación, p. 11.

23 Id., p. 4. 
en el Informe Bellmont, conocido como principialismo ${ }^{24}$ para atender asuntos entre médico y paciente o sujeto de investigación. Se basa en cuatro principios o normas morales generales: respeto por la autonomía, ${ }^{25}$ beneficencia, ${ }^{26}$ no maleficencia y justicia. ${ }^{27}$ Estos cuatro principios son normas morales generales de las que se derivan normas de conducta más específicas. Los principios se ponderan en función de las circunstancias concretas de cada caso para elegir el que emerja con mayor fuerza; pero esa ponderación no evita los conflictos entre los principios y normas concretas al aplicarlos a los casos particulares.

El principialismo jerarquizado, se refiere a que hay unos principios superiores: no maleficiencia y justicia, en la medida en que obligan con independencia de opinión y voluntad de los implicados. Según Diego Gracia, la no maleficiencia y la justicia se refieren a la ética del deber, a la ética de mínimos, de lo exigible a todos, son valores exigibles en la esfera pública, por lo que es lo que corresponde al derecho.
Mientras que, los principios de autonomía y la beneficiencia dependen del sistema de valores de la persona, de la ética de la felicidad, y son exigibles en la esfera privada. ${ }^{28}$

\section{Charles Foster ${ }^{29}$ presenta un} paradigma para atender situaciones en ética médica y bioética que postula que la dignidad humana es el único concepto útil, que sirve tanto para los casos difíciles como los fáciles; y cuando hay conflicto entre los principios y deberes. Entiende que hay situaciones en la ética médica en que las herramientas analíticas existentes como el principialismo no son suficientes. Propone darle a la dignidad un significado sustantivo y desarrolla un modelo que denomina "transactional model of deployment", en el cual el asunto de análisis ético o legal no es el paciente, el médico, la comunidad, o cualquiera otro, sino una transacción que constituye un encuentro bioético, cuyo propósito es maximizar la dignidad de todos. ${ }^{30}$ Este modelo basado en la dignidad, puede utilizarse tanto en los casos de bioética clínica como ante cualquier otro asunto bioético, no basado en la medicina, sino en la vida humana en general, la animal y ambiental.

\section{El concepto de dignidad hu- mana como base}

La dignidad es un concepto abstracto, que hay que darle contenido. La Dignidad es la base de todos los derechos del ser humano en Declaraciones y Tratados Internacionales ${ }^{31}$ y Constituciones. ${ }^{32}$ Entre las propiedades de la dignidad se reconocen las siguientes: consustancial a la naturaleza del género humano, intrínseca al ser humano, inviolabilidad, integridad física y moral, dignidad individual y de los demás, vida humanamente digna, autonomía, identidad personal, protección de datos personales, igualdad de los seres humanos ante la ley y ante los demás, y aplica después de la muerte.

Sulmasy identifica tres variantes en el uso de la palabra dignidad en el discurso moral; son ellas: valor intrínseco al ser humano, valor atribuido por otros y dignidad florecien-

24 Beauchamp y Childress, Principles of Biomedical Ethics. NY, Oxford U Press, 1978, 6ta ed. 2009.

25 Se refiere a la capacidad de autodeterminación de la persona libre de influencias externas y de limitaciones que impidan una genuina decisión. En el caso de personas con autonomía disminuida (e.g., niños, incapacitados mentales) se justifica que otra persona decida.

26 Se refiere a tomar la acción que represente el mejor interés de la persona. Los beneficios deben sobrepasar los riesgos o daños.

27 Entendido como lo que es debido a las personas, lo que les pertenece o corresponde en la comunidad. Acciones que promuevan la distribución equitativa de bienes, servicios y recursos.

28 Gracia D. Fundamentos de la Bioética, 2007.

29 Foster C. Human Dignity in Bioethics and Law. Oxford, Hart Pub., 2011.

$30 \quad$ Id., p. 15.

31 E.g. Declaración Universal de los Derechos Humanos, 1948 (preámbulo: dignidad e igualdad y derechos inalienables de la familia humana, Art. 1; 22, 23); Carta de Derechos fundamentales de la Unión Europea, 2000, Art. 1, y Tratado de Lisboa, Consejo de Europa, 2009; Convenio Europeo sobre Derechos Humanos y Biomedicina, 1997, Art. 1, Consejo de Europa (Oviedo) y protocolos adicionales; Organización de las Naciones Unidas, Declaración Universal de Bioética y Derechos Humanos, 2005, Preámbulo, Arts. 2(c), 2 (d), 3, 10, 11, 12; Naciones Unidas, Declaración Universal del Genoma, 1997, Arts. 1, 2, 10-12, 15, 21, 24.

32 E.g., Japón, 1946; Alemania 1949; Italia, 1948; Puerto Rico, 1952.

33 Sulmasy, D.P., "The varieties of human dignity: a logical and conceptual analysis", Med. Health Care and Philosophy, DOI 10.1007/s11019-012-9400-1.publicado en línea 27 de marzo de 2012. 
te. $^{33}$ La dignidad floreciente es un proceso que conlleva desarrollar la excelencia humana y que requiere el entendimiento previo de la condición de la dignidad intrínseca. El uso de la palabra dignidad como sinónimo de un valor que se le atribuye a una persona también presupone la cualidad intrínseca de la dignidad por el hecho de ser humano.

En el contexto bioético nos referimos a dignidad intrínseca cuando postulamos que el ser humano tiene la libertad de rechazar tratamiento médico e incluso escoger morir. En cambio, cuando un paciente está en su última etapa, atado a máquinas para extender su vida, decimos que eso "no es una muerte digna". En esa acepción la usamos como sinónimo de valor atribuido por otros, ya que ver a una persona en ese estado no corresponde a la concepción del ser humano independiente y saludable. En cambio, hablamos de la dignidad floreciente cuando una persona en estado de muerte demuestra valor, coraje y permite que los familiares le den cierre a ese proceso, aun cuando está en dolor físico y sabe que la muerte es inevitable.

El concepto de dignidad ha sido parte del desarrollo del pensamiento de la humanidad. En el mundo antiguo, los estoicos postulaban que todos los hombres tenían dignidad por su racionalidad intrínseca. ${ }^{34}$ En la tradición judeo- cristiana se entiende que el ser humano es hecho a la imagen de Dios, lo que le concede dignidad intrínseca. Pero no es hasta el renacimiento en que se le reconoce a la dignidad la propiedad de la autonomía, con Pico de la Mirandola, para quien "el hombre por ser humano se considera digno, su naturaleza es racional y el resultado es la autonomía para tomar decisiones." 35

Para Kant, el ser humano es un fin en sí mismo, de allí su máxima, "obra de tal modo que uses la humanidad, tanto en tu persona como en la de cualquier otro, siempre como un fin y nunca solo como un medio". ${ }^{36}$ El ser humano, se considera como un fin en sí mismo y no tiene valor relativo como precio, sino un valor intrínseco, la dignidad. No está basado en el valor otorgado por otros, ni en la excelencia, sino en la humanidad en sí misma. Es el valor de las personas por el mero hecho de ser humanos, por su naturaleza. No es conferido o creado por decisiones humanas, sino que es primario y anterior a los atributos humanos.

Dworkin entiende que es la dignidad intrínseca del ser humano (objective dignity) lo que hace que los derechos humanos básicos sean universales. ${ }^{37}$

Foster, entiende que dignidad no es sólo una propiedad consustancial al ser humano, sino el proceso de florecer como ser humano (objective human flourishing)..$^{38}$ Presenta un modelo práctico, o transaccional para la deliberación de casos en bioética y derecho. Propone que se busque en toda posible solución a un problema bioético, el curso de acción que optimice la dignidad en el mundo. Ello implica considerar al paciente, los familiares, el personal médico, la comunidad, y resolver el asunto teniendo como meta maximizar la dignidad, entendida como el más pleno desarrollo de lo humano en cada una de las personas involucradas. Respetar la dignidad del otro no es solo respetar su humanidad, sino también su propia dignidad y la de la especie.

\section{La dignidad en Puerto Rico}

En Puerto Rico, el reconocimiento a la dignidad del ser humano tiene prioridad en la Constitución, ${ }^{39}$ y de la misma emanan otros derechos tales como la igualdad ante la ley, el derecho a la intimidad, la libertad de religión, el debido proceso. ${ }^{40}$ De manera que, en un modelo adjudicativo de contro-

\footnotetext{
Abbagnano, N., Diccionario de Filosofía. Barcelona, Montaner y Simon, 1964: vol.1, pp.141-149.

On the Dignity of Man, 1486, citado en C. Foster, Human Dignity in Bioethics and Law, 2011: p.34.

Kant, E., Fundamentación de la metafísica de las costumbres. Barcelona, Editorial Ariel, 1996.

Dworkin, R. Justice for Hedgehogs, 2011.

Foster, op. cit.: 15.

39 El texto constitucional lee: "La dignidad del ser humano es inviolable. Todos los hombres son iguales ante la ley. No podrá establecerse discrimen alguno por motivo de raza, color, sexo, nacimiento, origen o condición social, ni ideas políticas o religiosas. Tanto las leyes como el sistema de instrucción pública encarnarán estos principios de esencial igualdad humana." Art. II, Sec. 1, Constitución del Estado Libre Asociado de Puerto Rico.

40 "El propósito de esta sección es fijar claramente como base consustancial de todo lo que sigue el principio de dignidad del ser humano, y, como consecuencia de ésta, la igualdad esencial de todas las personas dentro de nuestro sistema constitucional." Diario de Sesiones de la Convención Constituyente de Puerto Rico, San Juan Lexis-Nexis, edición conmemorativa, 2003: p. 256.
} 
versias en bioderecho, el principio fundamental para resolver los llamados casos difíciles es la dignidad. El concepto dignidad debe considerarse en toda la amplitud de sus propiedades y acepciones. Es éste el límite de riesgo entre lo que es permitido y lo que no es permitido. $\mathrm{Si}$ atenta contra la dignidad el ser humano no es permitido.

Un ejemplo de la aplicación del concepto de dignidad humana en la adjudicación

En Lozada Tirado v. Tirado Flecha, 177 DPR 893 (2010) se cuestiona la constitucionalidad de la Ley de Voluntades Anticipadas ${ }^{41}$ por limitar su aplicabilidad a casos en que la persona posee una condición de salud terminal o estado vegetativo persistente. La controversia a dilucidar era si era válida una declaración previa de voluntad suscrita por una persona que, por sus creencias religiosas, decidió rechazar transfusiones de sangre en cualquier circunstancia y sin sujeción a condición de salud alguna aun cuando ello implicara peligro mortal para su vida. ¿Es ejecutable un documento de este tipo aun en circunstancias no contempladas específicamente por la ley? El Tribunal concluyó afirmativamente y declaró inconstitucional la disposición de ley que limitaba la declaración previa de voluntad a los casos en que la persona estaba en un estado de salud terminal o en estado vegetativo persistente, según definidos en la ley.
El Tribunal Supremo de Puerto Rico reconoce el derecho del paciente adulto a rechazar tratamiento médico incluso necesario para salvar su vida, en cualquier circunstancia, como parte de sus derechos: dignidad, intimidad, libertad de religión, e interés libertario del debido proceso de ley. Este derecho no está supeditado a las creencias morales o juicios subjetivos de otras personas sobre esa conducta ${ }^{42} \mathrm{O}$ a prohibiciones impuestas por el Estado. Al referirse al derecho a la dignidad la opinión del Tribunal indica:

"La Carta de Derechos de la Constitución del Estado Libre Asociado de Puerto Rico consagra el principio cardinal de la inviolabilidad de la dignidad del ser humano. Art. II, Sec. 1, Const. E.L.A. A base de ello, reconoce como derechos fundamentales la intimidad y la protección contra ataques abusivos a la honra, la reputación y la vida privada o familiar. Art. II, Secs. 1 y 8 , Const. E.L.A., Estos derechos tienen especial preeminencia en nuestro esquema constitucional. Soc. de Gananciales v. Royal Bank de P.R., 145 D.P.R. 178, 201 (1998). A la luz de las referidas disposiciones constitucionales, hemos resuelto que el Estado tiene una función dual para proteger los derechos allí contenidos: abstenerse de actuar de manera tal que se viole el ámbito de autonomía e intimidad indi- vidual y actuar afirmativamente en beneficio del individuo. Íd." ${ }^{43}$

La opinión de conformidad de la Juez Asociada Anabelle Rodríguez abunda en la dignidad de la persona.

"[P]odemos aseverar que la dignidad humana tiene como fundamento la propia libertad y autonomía del individuo. Véase, G. Peces-Barba Martínez, La Dignidad de la Persona desde la Filosofía del Derecho, Dykinson, 2003, 2da ed., Madrid, págs. 68-69. Ésta "supone algo más que la mera garantía negativa de que la persona no va a ser objeto de ofensas o humillaciones, sino que supone también la afirmación del pleno desarrollo de la personalidad de cada individuo. El pleno desarrollo de la personalidad implica, a su vez, de un lado, el reconocimiento de la total autodisponibilidad, sin interferencias o impedimentos externos, de las posibilidades de actuación propias de cada hombre; de otro, la autodeterminación que surge de la libre proyección histórica de la razón humana, antes que de una predeterminación dada por la naturaleza de una vez por todas." (Bastardillas en original.) Galán Juárez, Intimidad, Nuevas dimensiones de un viejo derecho, Editorial universitaria Ramón Areces, Madrid, 2004, págs. 116-117. Es, a fin de cuentas, como nos recuerda el profesor Peces-Barba, "un proyecto que debe realizarse

\footnotetext{
41 Puerto Rico, Ley Núm. 160-2001.

42 "Es nuestro criterio que la evaluación del rechazo de un paciente a cierto tratamiento médico por razones religiosas o de conciencia, no debe basarse en un juicio subjetivo sobre dicha conducta, sino en el respeto a la dignidad humana y a la libertad individual y de culto de esa persona, la cual sólo podría verse limitada por un interés mayor del Estado." Lozada Tirado, 177 DPR 893, a la p. 933. Esta cita es importante por cuanto especifica que la evaluación no puede estar supeditada a los juicios morales de otras personas o de grupos de interés que pretendan imponer sus creencias personales.

43177 DPR 893 (2012) a la p. 910.
} 
y conquistarse." Peces-Barba Martínez, op. cit., pág. 68.

La dignidad humana es por lo tanto una empresa continua de autorrealización que se manifiesta en la autodeterminación consciente y responsable de la propia vida y que lleva consigo la pretensión al respeto por parte de los demás. En similar tenor se expresa el profesor $\mathrm{Hi}$ ram Meléndez Juarbe al señalar: "[T] he most diverse authorities on the subject have recognized that human dignity is generally associated with the notion of respect for the intrinsic worth of every person or, in a word, 'personhood'. Those who have tried to give precise content to this principle have identified, as an important corollary, the protection of autonomous choice in the development of personal identity. For one commentator human dignity entails that 'a high priority should be accorded in political, social and legal arrangements to individual choices in such matters as belief, way of life, attitudes and the conduct of public affairs."” (Bastardillas en original.) (Citas omitidas.) H. Meléndez Juarbe, Privacy in Puerto Rico and the Madman's Plight: Decisions, 9 Geo. J. Gender \& L. 1, 45 (2008)." ${ }^{44}$

\section{Colón vda. Rivera vs. Romero Barceló: otro ejemplo}

La dignidad del ser humano prevalece aun después de la muerte. En Colón vda. Rivera vs.
Romero Barceló, 112 DPR 573 (1982), se presenta una acción en daños e injunction, para detener la publicación como parte de una campaña publicitaria de una fotografía del cadáver de un familiar asesinado durante un asalto. El Tribunal indicó que el uso de la foto en la campaña violó sus derechos constitucionales a la intimidad, personalidad, vida privada y familiar y honor. En este caso el Tribunal Supremo de Puerto Rico no tenía un precedente para atender el asunto y en el caso anterior la ley estaba en conflicto con los derechos constitucionales.

\section{Modelo de Adjudicación PRopuesto}

Un modelo de adjudicación para atender asuntos en bioderecho que se enriquezca del modelo de deliberación bioética ${ }^{45}$ podría ser como sigue:

- Precisar los hechos;

- Identificar controversias jurídicas y fácticas;

- Identificar las decisiones de los tribunales inferiores en el caso y fundamentos jurídicos de las mismas;

- Identificar los problemas éticos, valores, principios y normas jurídicas en conflicto;

- Consideración de cursos de acción extremos, intermedios; ¿cuál es el valor principal amenazado?;

- Selección del curso de acción óptimo y la justificación ética;

- Identificar los principios constitucionales, disposicio- nes de ley y jurisprudencia que mejor aplique y;

- Decisión final y fundamentos legales.

Procedo a explicar esto modelo decisorio integrando aspectos propios de la deliberación en bioética que podrían ser útiles en el proceso decisorio en derecho cuando el juez se enfrente a decidir asuntos en bioderecho.

Hechos. La adjudicación de toda controversia en derecho requiere identificar los hechos pertinentes. ¿Qué, quién, cómo, dónde, con quién, cuándo, por qué? En asuntos de bioética médica el modelo de Jonsen, Siegler y Winsdale ${ }^{46}$ aporta un esquema exhaustivo de investigación de los hechos. Este modelo podría ser útil en el análisis de los hechos que puedan ser pertinentes al proceso decisorio de un caso legal que presente asuntos de bioética clínica. No obstante, el modelo propuesto en este escrito no se limita a asuntos de bioética clínica. El modelo de Jonsen et al. organiza el análisis de los hechos según los aspectos médicos, las preferencias del paciente, la calidad de vida y los aspectos contextuales. Los mismos se discuten en los párrafos que siguen.

Los aspectos médicos incluyen considerar el problema clínico, tipo de intervención, metas de tratamiento, evaluación de opciones, discusión ética de las mismas, beneficios y daños

44 Lozada Tirado vs Tirado Flecha, 177 DPR 893, 945-946.

45 Este modelo de deliberación adjudicativa para casos en bioderecho, que se nutre de la deliberación bioética, lo he estado trabajando con la Dra. Marlén Oliver Vázquez, Directora Asociada del Instituto de Bioética y Catedrática de la Escuela de Salud Pública del Reciento de Ciencias Médicas. Versiones previas se presentaron en seminarios que hemos impartido conjuntamente en la Academia Judicial (2012) y la Facultad de Derecho, Universidad Interamericana, (curso de biojurídica, 2011; y seminarios en educación continuada, 2011 y 2012).

46 Jonsen, A., Siegler M., y Winsdale, W., Clinical Ethics, McGraw-Hill, $5^{\text {th }}$ ed. 2002. 
posibles. En cuanto a las preferencias del paciente se analizan sus preferencias de tratamiento, sus valores e información con que cuenta para tomar una decisión, apreciación de riesgos y beneficios, y si prestó un consentimiento informado, o si hay directrices anticipadas, testamento vital o poder duradero.

El respeto por la autonomía de la persona es la base tanto en bioética como en derecho, cuando se trata de las preferencias del paciente. En derecho estos aspectos se examinan desde el interés libertario reconocido bajo la cláusula del debido proceso a tomar decisiones informadas sobre el cuidado médico, incluyendo el rechazo a tratamiento, y el derecho a la intimidad en la toma de decisiones.

En el cuadrante de calidad de vida se analizan las características de vida de la persona antes y después del tratamiento médico pertinente. En esta parte, desde la óptica médica priman los principios de beneficiencia, no maleficiencia y autonomía. En derecho se considera el derecho a una vida y muerte digna, protegidos por los derechos constitucionales a la dignidad, intimidad, e interés libertario.

En cuanto al grupo de aspectos contextuales se consideran los asuntos familiares, religiosos, culturales, sociales e institucionales que pueden influir en la decisión; las implicaciones legales y financieras de determinado tratamiento o decisión; y posibilidades de éxito y res- tricciones del contexto. El principio de justicia distributiva (la salud entendida como un bien primario que debe distribuirse equitativamente, el acceso y distribución de los servicios de salud) es pertinente. La libertad religiosa se reconoce como un derecho fundamental desde la óptica del derecho.

Controversias. El segundo paso en el modelo es la identificación del asunto o controversias a resolver por el tribunal.

\section{Decisión de tribunales inferio-} res. En casos a nivel apelativo el análisis de la decisión del tribunal inferior y su fundamentación jurídica es paso previo al proceso decisorio en el tribunal de apelación. Este debe formularse de forma precisa pues será objeto de análisis y deliberación en los pasos siguientes del modelo.

El proceso decisorio o la deliberación. Deliberar se define como "considerar atenta y detenidamente el pro y el contra de los motivos de una decisión, antes de adoptarla, y la razón o sinrazón de los votos antes de emitirlos." ${ }^{47}$ Diego Gracia indica que se delibera sobre lo que puede ser o hacerse de otra manera; no se busca consenso, sino enriquecer el análisis para tomar la decisión más prudente. ${ }^{48}$ Trías Monge concluye su libro Teoría de Adjudicación indicando que "no habrá soluciones únicas y mágicas a los conflictos que el juez confronte; lo rondará siempre la intranquilidad sobre si lo que resuelva como juez es lo que mejor sirve a los valores de la vida buena y de una sociedad justa... pero esa intranquilidad de conciencia...es fuerza que lo obligará a la búsqueda incesante de una justicia objetiva hasta donde exista o esté a su alcance." 49

La identificación de problemas éticos, valores, principios, normas jurídicas y derechos en conflicto debe ser paso previo a la deliberación sobre los cursos posibles de acción. La intención es armonizarlos dando prioridad al derecho más fundamental. La evaluación de asuntos éticos o de valores no puede estar supeditada a los juicios morales de otras personas o grupos de interés que pretendan imponer sus creencias personales, algunas de corte religioso. Véase a esos fines las expresiones del Tribunal en Lozada Tirado vs. Tirado Flecha, "es nuestro criterio que la evaluación del rechazo de un paciente a cierto tratamiento médico por razones religiosas o de conciencia, no debe basarse en un juicio subjetivo sobre dicha conducta, sino en el respeto a la dignidad humana y a la libertad individual y de culto de esa persona, la cual sólo podría verse limitada por un interés mayor del Estado." 50

En el proceso decisorio es también necesario identificar y ponderar los posibles cursos de acción: extremos, intermedios. En cada uno de los posibles cursos de acción determinar el valor principal amenazado; contrastar los principios y derechos involucrados, determinar si se infringe algún derecho; evaluar las consecuencias previsibles. Ese ejer-

\footnotetext{
47 Diccionario Real Academia, ed. 22.

48 Gracia, D., Fundamentos de la bioética, 2007.

49 Trías Monge, J., Teoría de la Adjudicación, 2001: p. 419

50177 DPR 893, 933
} 
cicio de deliberación debe llevar a la selección del curso de acción óptimo, o el más prudente, dentro de la legalidad.

Los principios constitucionales (teniendo presente que la dignidad es la base de los demás derechos constitucionales), las disposiciones de ley y jurisprudencia que mejor aplique a la decisión fundamentarán legalmente la decisión.

\section{CONCLUSIÓN}

En asuntos de bioderecho, la vía judicial parece ser la más adecuada. Tratándose de asuntos muy personales para cada persona, en que no hay consenso social, la mejor forma de abordarlos es caso a caso. El modelo decisorio propuesto para casos en bioderecho reconoce como derecho más fundamental a la dignidad del ser humano. En términos de teoría de adjudicación han influido Dworkin, Foster y Trias Monge. En bioética, el principialismo jerarquizado es la mejor opción, pero hay casos en que se queda corto entre otros, cuando la persona no puede ejercer su autonomía, por limitaciones en su capacidad racional (e.g., niños, incapacitados mentales, desigualdad social) o situaciones que violan la dignidad de la persona después de su muerte. De ahí que el modelo de derecho basado en la dignidad floreciente sirve para esos casos. La bioé- tica puede servirse de este modelo de argumentación jurídica cuando aborde conflicto entre los principios.

\section{RefERENCIAS BIBLIOGRÁFICAS}

Abbagnano, N. (1964) Diccionario de Filosofía. Barcelona, Montaner y Simon, vol.1.

Aparisi Millares, A. (2008) Bioética Bioderecho y Biojurídica, 2008. En http://www2. uah.es/filder/bioetica_bioderecho_biojuridica.pdf (consultado 1/03/2013).

Beauchamp T. L. y Childress J. F. (1978, ed. 2009) Principles of Biomedical Ethics, New York, Oxford University Press.

Cely Galindo,G., (2009) Bioética Global. Madrid, Siglo del hombre.

D 'Agostino, F., "Bioética y Derecho," Acta Bioethica, año 8 , núm. 2

DPR. Decisiones del Tribunal Supremo de Puerto Rico.

Dworkin, R., (2011). Justice for Hedgehogs, Harvard U Press. ...- (1978, 5ta ed. 1987). Taking Rights Seriously. Harvard U. Press.

Ferrer, J.J. (2007). Deber y Deliberación, Mayagüez. CEPA;
Foster, C. (2011). Human Dignity in Bioethics and Law, Oxford, Hart Publishing.

Garrafa, Volnei (2007) Revista Brasileira de Bioética 3(3):344-359 Epistemiología de la Bioética- enfoque latinoamericano.

Gracia, D. (2007) Fundamentos de la bioética, Madrid, Triacastela.

Hart, H.L. (1997) The Concept of Law, Oxford Univerity Press.

Jonsen, A., Siegler M., y Winsdale, W., (5ta ed. 2002; rev 2010) Clinical Ethics, McGraw-Hill.

Kant E. (1996), Fundamentación de la metafísica de las costumbres. Barcelona, Editorial Ariel.

Sulmasy, D.P., "The varieties of human dignity: a logical and conceptual analysis", Med.

Health Care and Philosophy, DOI 10.1007/s11019-0129400-1.publicado en línea 27 de marzo de 2012.

Trías Monge, J. (200) Teoría de la Adjudicación, San Juan, Editorial UPR.

Vila-Coro, M. (1995). Introducción a la Biojurídica. Madrid, Universidad Complutense. 